\title{
Over-the-Counter Herbal Weight Loss Supplements in Egypt: Label Claim, Microbiological and Pharmaceutical Quality, and Safety Assessments
}

\author{
Nada Ahmed ${ }^{a}$ Mohamed Ismail Nounou $^{b} \quad$ Alaa Abouelfetouh ${ }^{c} \quad$ Amal El-Kamel $^{a}$ \\ a Department of Pharmaceutics, Faculty of Pharmacy, Alexandria University, Alexandria, Egypt; ${ }^{b}$ Department of Pharmaceutical \\ Sciences, University of Saint Joseph, School of Pharmacy and Physician Assistant Studies (SPPAS), Hartford, CT, USA; \\ 'Department of Microbiology and Immunology, Faculty of Pharmacy, Alexandria University, Alexandria, Egypt
}

\section{Significance of the Study}

- Our study highlights the potential risks of illegal weight loss products. Not only were possible adulterants quantified, but also the pharmaceutical quality of the formulations, their inter- and intra-batch variability, and their safety were assessed. We report a situation of adulterated nutraceuticals in the Middle East and highlight possible drastic outcomes and deadly scenarios for consumers.

\section{Keywords}

Nutraceuticals $\cdot$ Herbal supplements · Sibutramine $\cdot A B$ Slim $\cdot$ Retrospective prevalence $\cdot$ Adulteration $\cdot$ Sildenafil $\cdot$ Sterility test

\begin{abstract}
Objectives: Nutraceuticals are advertised and sold with the label claim of being natural and safe herbal products. Due to the absence of clear regulations and guidelines for safety assessments of these products, nutraceuticals are commonly adulterated in order to increase sales. The objective of the current study was to design a comprehensive evaluation system to assess the safety, efficacy, authenticity according to label claim, and pharmaceutical quality of herbal slimming products in between 2015 and 2017. Methods: We designed a comprehensive assessment system to evaluate the safety, authenticity according to label claim, and pharmaceutical quality of slimming nutraceuticals. Six different popular
\end{abstract}

\begin{tabular}{ll}
\hline KARGER & $\begin{array}{l}\text { ( ) 2019 The Author(s) } \\
\text { Published by S. Karger AG, Basel Openger }\end{array}$ \\
E-Mail karger@karger.com & $\begin{array}{l}\text { This is an Open Access article licensed under the Creative Commons } \\
\text { Attribution-NonCommercial-4.0 International License (CC BY-NC) } \\
\text { (http://www.karger.com/Services/OpenAccessLicense), applicable to } \\
\text { the online version of the article only. Usage and distribution for com- } \\
\text { mercial purposes requires written permission. }\end{array}$
\end{tabular}

products were evaluated (Zotreem Plus ${ }^{\circledR}$, Zotreem Extra ${ }^{\circledR}$, Malaysian Super Slim ${ }^{\circledR}$, AB Slim ${ }^{\circledR}$, Chinese Super Slim ${ }^{\circledR}$, and Metabolites $\left.{ }^{\circledR}\right)$. The pharmaceutical evaluation included analyzing the samples via high-performance liquid chromatography to determine any possible adulterants. Additionally, the products' physical properties were assessed via pharmacopeial tests. Finally, a microbial evaluation and a cross-sectional observational retrospective prevalence study were conducted to assess the products' safety and efficacy. Results: The tested products were found to be adulterated with unreported active pharmaceutical ingredients such as sibutramine, sildenafil, phenolphthalein, and orlistat. Furthermore, they contained heterogeneous amounts of adulterants and exhibited an unsatisfactory pharmaceutical and microbial quality. Finally, the observational survey conduct-

N.A. and M.I.N. contributed equally and are considered co-first authors. 
ed on users showed that high percentages of participants suffered from common side effects such as depression, diarrhea, and hypertension. Conclusions: These products threaten the health of consumers. There is a need to raise awareness of the lethal consequences of illegal nutraceuticals.

(c) 2019 The Author(s)

Published by S. Karger AG, Basel

\section{Introduction}

A nutraceutical is a health-promoting product which enhances physical and mental activities of the body. Moreover, it is advertised to reduce the risk factors for different diseases [1]. A nutraceutical formulation is simply a hybrid between food and drug [2]. Around $50 \%$ of the population in USA consumes nutraceuticals and herbal and dietary supplements [3]. This illustrates the wide spread of nutraceuticals sold globally with the claim of being natural herbal products [4]. Due to the absence of regulations and laws on assessing guidelines regarding the safety and efficacy of these products, so-called natural weight loss products are usually adulterated to increase sales [5].

Obesity is the accumulation of fat in adipose tissues in an abnormal or excessive manner leading to health impairment [6]. As reported in WHO global estimates for 2018 , more than 1.9 billion adults (39\%) were considered overweight at the age of 18 years or older in 2017 [7]. It is predicted that the percentage will increase to $60 \%$ by 2020 [8]. Obesity can be a leading cause of many serious health problems, such as high blood pressure, cancer, type 2 diabetes, heart diseases, stroke, erectile dysfunction, nonalcoholic fatty liver disease, and other health complications [8]. A healthy diet plan and regular physical activity would help in losing weight and maintaining weight loss in the long term [9]. On the other hand, some people consume approved weight loss products, such as orlistat, lorcaserin, phentermine, and topiramate, or slimming nutraceuticals [9] to speed up the process of weight loss [9].

Weight loss medications are attractive, easy options for losing weight. Historically, the first slimming elixirs described by Soranus of Ephesus, a Greek physician in the 2nd century $\mathrm{AD}[10]$, were laxatives and purgatives; furthermore, the British physician Nathaniel Edward YorkeDavies reported on subjects who lost weight by consuming desiccated thyroids in 1894 [11]. Unfortunately, most people are attracted to the use of herbal weight loss products because of the misconception that these products are safe. However, nutraceuticals may contain FDA-banned ingredients such as sibutramine and phenolphthalein [12]. Chemical adulterants in weight loss nutraceuticals have many side effects, which may lead to heart failure, cancer, and other life-threatening conditions [13]. Moreover, they may contain stimulants such as caffeine and sibutramine that are addictive and may cause many side effects including insomnia, depression, suicidal thoughts, and heart attacks, which could be fatal [14]. Therefore, these products are contraindicated in people with panic attacks, hypertension, anxiety, and heart problems [13]. Alarmingly, these diet pills could be misused by consuming more than the recommended dose to speed up the process of weight loss, which may lead to addiction or overdose toxicity [15]. Sibutramine, levothyroxine, sildenafil, phenolphthalein, orlistat, bumetanide, fenfluramine, fenproporex, furosemide, cetilistat, fluoxetine, rimonabant, and phenytoin are the most common adulterants in counterfeit weight loss nutraceuticals [16].

The main objective of the current study was to design a comprehensive evaluation to assess the safety, efficacy, authenticity according to label claim, and pharmaceutical quality of herbal slimming products. Herbal slimming nutraceuticals in the market are claimed to be $100 \%$ herbal and to aid in weight loss without any side effects. The nutraceutical products analyzed in our study are $A B$ Slim ${ }^{\circledR}$, Zotreem Plus ${ }^{\circledR}$, Zotreem Extra ${ }^{\circledR}$, Chinese Super Slim ${ }^{\circledR}$, Malaysian Super Slim ${ }^{\circledR}$, and Metabolites ${ }^{\circledR}$.

Pharmaceutical evaluation of the various nutraceuticals included analyzing the samples via high-performance liquid chromatography (HPLC) to determine any possible adulterants in the evaluated products. Additionally, the products' physical properties were assessed via pharmacopeial tests, including weight variation and disintegration tests, to evaluate the pharmaceutical quality and inter- and intra-batch heterogeneity within and across different batches of these nutraceuticals. Additionally, a microbial evaluation was conducted to assess the safety of these products. Finally, to assess the safety, efficacy, and pattern of use of the products, a cross-sectional observational retrospective prevalence study was carried out. In this study, a new survey to assess the safety, efficacy, and pattern of use of the investigated products was developed and validated.

\section{Materials and Methods}

Materials

Zotreem Plus ${ }^{\circledR}$ (MTCO Company, Hong Kong, China), Zotreem Extra $^{\circledR}$ (MTCO Company), Malaysian Super Slim ${ }^{\circledR}$ (Majestic Group Australia P/L, Kuala Lumpur, Malaysia), AB Slim ${ }^{\circledR}$ 
(AB Care Medical Herbs, Beirut, Lebanon), Chinese Super Slim ${ }^{\circledR}$ (Yunnan Menghuang Trade Company, Hong Kong, China), and Metabolites ${ }^{\circledR}$ (Simildiet Laboratorios, Zaragoza, Spain) were purchased from different pharmacies in Alexandria, Egypt, between October 2015 and February 2017 in triplicate packages from different batches. All solvents and chemicals used were of analytical grade.

\section{Pharmaceutical Evaluation: HPLC Analysis}

An Agilent ${ }^{\mathrm{TM}}$ HPLC device (Agilent ${ }^{\mathrm{TM}} 1260$ Infinity, Quaternary Pump-G1311C, DAD-G1315D, Auto Inj-G1329B; Agilent Technologies, Germany) was used. A reversed-phase $\mathrm{C}_{8}$ column (Waters; $150 \times 3.9 \mathrm{~mm}$, particle size $=5 \mu \mathrm{m}$, pore size $=100 \AA$ ) was used as a stationary phase. The mobile phase was a gradient system composed of $20 \mathrm{~mm}$ aqueous ammonium formate (A) and acetonitrile (B). The run time of the gradient elution program and the injection volume were $32 \mathrm{~min}$ and $20 \mu \mathrm{L}$, respectively $\left(37^{\circ} \mathrm{C}, 1 \mathrm{~mL} /\right.$ min flow rate), to simultaneously separate and quantify five possible adulterants: thyroxine, phenolphthalein, sibutramine, sildenafil, and orlistat. The gradient elution program started with an isocratic gradient of $\mathrm{A}: \mathrm{B} 90: 10 \mathrm{v} / \mathrm{v})$ for $3 \mathrm{~min}$ (0th to $3 \mathrm{rd} \mathrm{min})$. The ratio of A linearly decreased to $50 \%$ within $2 \mathrm{~min}$ (3rd to 5 th $\mathrm{min}$ ) and was sustained at the same ratio for $2 \mathrm{~min}$ (5th to 7 th $\mathrm{min}$ ). The composition of the mobile phase linearly changed to A:B 25:75 (v/v) for $2 \mathrm{~min}$ (7th to 9 th $\min$ ), 15:85 (v/v) for $2 \mathrm{~min}$ (9th to 11th $\mathrm{min}), 5: 95(\mathrm{v} / \mathrm{v})$ for $11 \mathrm{~min}$ (11th to $22 \mathrm{nd} \mathrm{min}$ ), and finally 90:10 $(\mathrm{v} / \mathrm{v})$ for $10 \mathrm{~min}$ (22nd to $32 \mathrm{nd} \mathrm{min})$. A photodiode array detector was used at $\lambda_{\max }$ of $285 \mathrm{~nm}$ for phenolphthalein, $213 \mathrm{~nm}$ for orlistat, and $224 \mathrm{~nm}$ for thyroxine and sibutramine detection. The retention times for thyroxine, phenolphthalein, sibutramine (Sunshine Organic Co., Mumbai, India), sildenafil (gift from Bayer Inc., Leverkusen, Germany), and orlistat (European Egyptian Pharmaceutical Industries, Alexandria, Egypt) were 1.642, 7.787, 9.751, 11.435 , and $15.933 \mathrm{~min}$, respectively. The HPLC method was validated for reliable concomitant quantification.

The capsules were extracted in HPLC-grade methanol by emptying and transferring each capsule's content into a $10-\mathrm{mL}$ centrifuge tube. The contents were dispersed in $10 \mathrm{~mL}$ methanol and shaken for $10 \mathrm{~min}$ using a vortex mixer. The dispersions were sonicated for $15 \mathrm{~min}$ and centrifuged at 10,000 rpm for $10 \mathrm{~min}$ at room temperature. The supernatant was filtered into 1.5-mL Eppendorf tubes using a $0.22-\mu \mathrm{m}$ nylon filter.

\section{Pharmacopeial Tests}

Weight variation assessment [17] and disintegration testing [17] were performed as described by the United States Pharmacopeial Convention (The United States Pharmacopeia, USP 40-NF 35) [18].

\section{Microbiological Evaluation}

Microbiological assessments, including the total aerobic microbial count (TAMC) and total yeast microbial count (TYMC), of 3 different batches of AB Slim ${ }^{\circledR}$, Chinese Super Slim ${ }^{\circledR}$, Malaysian Super Slim ${ }^{\circledR}$, Zotreem Extra ${ }^{\circledR}$, and Zotreem Plus ${ }^{\circledR}$ were conducted as described by the United States Pharmacopeial Convention (The United States Pharmacopeia, USP 40-NF 35) [19]. Salmonella was detected using Rappaport Vassiliadis Salmonella Enrichment broth and subsequent growth on xylose lysine deoxycholate agar plates at $30-35^{\circ} \mathrm{C}$ (red colonies with a black center). Escherichia coli was detected by growth on MacConkey Broth at $42-44^{\circ} \mathrm{C}$, then on MacConkey agar plates at $30-35^{\circ} \mathrm{C}$; indole production was tested as described by USP 40-NF 35 [19]

The membrane filtration technique was adopted to carry out the sterility test on 3 different batches of Metabolites ${ }^{\circledR}$ injection, according to the guidelines of USP 40-NF 35 [19]. Suitability tests, including medium sterility and promotion of growth of aerobes, anaerobes, and fungi, were done before the sterility test according to the guidelines of USP 40-NF 35 [19]. Sterile tryptic soy broth (TSB) supplemented with Tween 80 was used as a negative control for the detection of Salmonella, TAMC, and TYMC on xylose lysine deoxycholate, tryptic soy agar, and Sabouraud plates, respectively.

Cross-Sectional Observational Retrospective Prevalence Study

The cross-sectional observational retrospective prevalence study was conducted in Egypt on users of diet clinics during October 2015 and October 2017 to assess the safety and efficacy of the prescription medications $\left(\right.$ Orly ${ }^{\circledR}$ generics, Chromax ${ }^{\circledR}$ generics, Chitocal ${ }^{\circledR}$ generics, and Cidophage ${ }^{\circledR}$ generics) and the nutraceutical over-the-counter (OTC) products (Super Slim ${ }^{\circledR}$, Zotreem Plus ${ }^{\circledR}$, AB Slim ${ }^{\circledR}$, Zotreem Extra ${ }^{\circledR}$, and Metabolites ${ }^{\circledR}$ ) for weight loss.

A clinical survey had been designed in Arabic to evaluate the use, safety, and efficacy of nutraceuticals among users. A pretest of the developed survey was performed on 30 individuals of different cultural background and socioeconomic status, and evaluated by 6 psychiatrists, 10 pharmacists, and 10 nutritionists. The individuals were consulted to ensure the completeness and the proper understanding of each question of the designed survey. The survey was delivered to 4,638 subjects on visits to different diet clinics. In all, $11.06 \%(n=513)$ of the participants successfully completed the survey. The subjects were randomly selected from different geographical locations in Alexandria.

The survey contained 64 questions and was divided into 3 main parts. The first part included questions about demographics such as date of birth, gender, weight, length, marital status, and educational level. The second part included questions about the use of weight loss products and participants' observations with respect to the safety and efficacy of the weight loss products used. The third part consisted of questions about participants' health and lifestyle, such as disease history, medications, smoking status, dietary habits, and physical activities.

\section{Statistical Analysis}

The statistical analysis of the data was performed using GraphPad $^{\text {TM }}$ Prism 7 (GraphPad, San Diego, CA, USA) and IBM SAS ${ }^{\text {TM }}$ 9.31. One-way and two-way analysis of variance along with Bonferroni's multiple comparison tests and multiple linear regression were used in the statistical analysis, with $p<0.05$ considered to be statistically significant.

\section{Results}

All capsules from the different batches of weight loss products were inspected physically with respect to content and shell prior to the various analyses. The analyzed products showed nonuniformity in the capsules' content, 


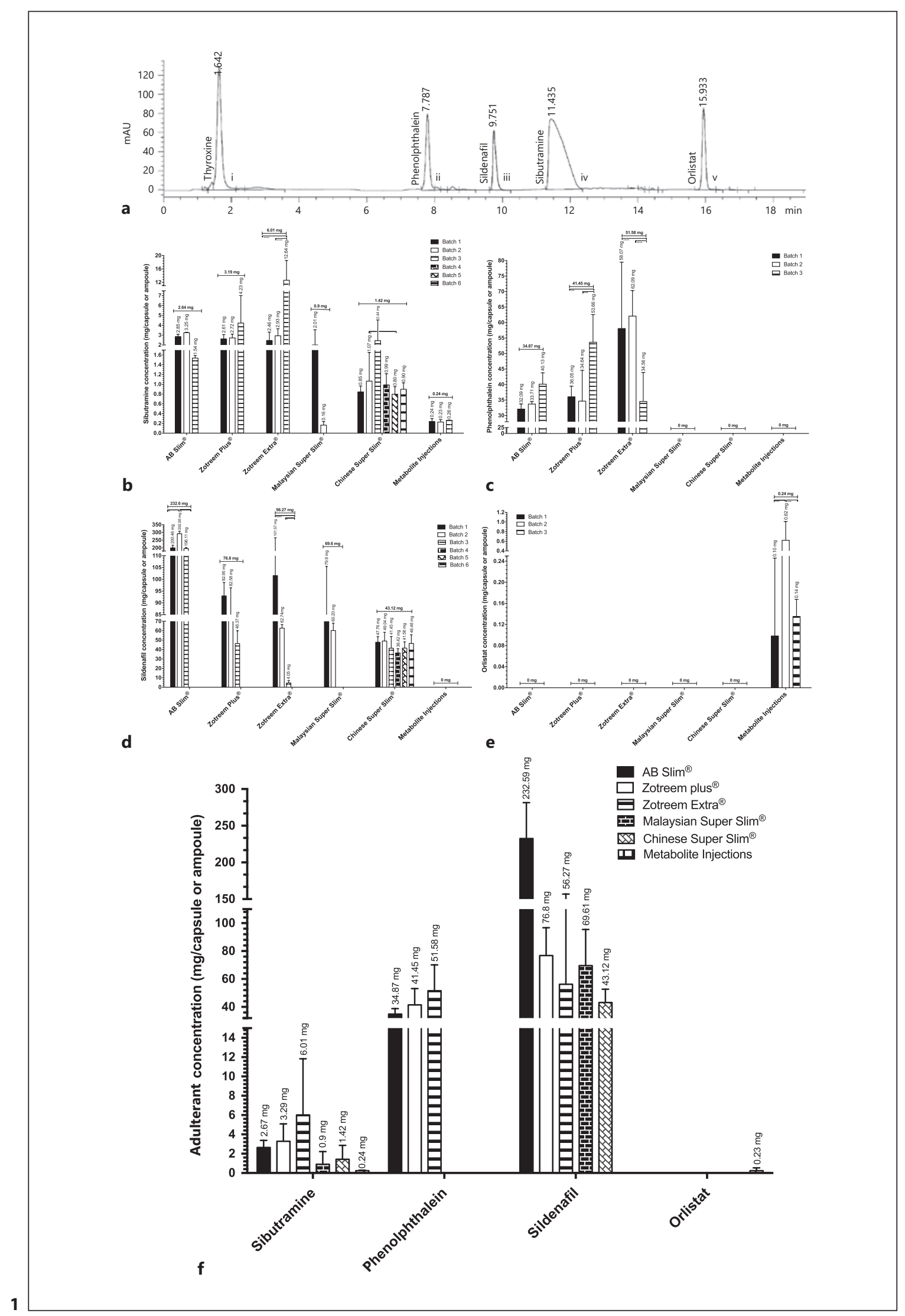

(For legend see next page.) 
color, and physicochemical properties (data not shown). The shell colors of capsules of the different batches of Zotreem Extra ${ }^{\circledR}$ were heterogeneous, with some batches pink and others red. The shells of capsules of the different batches of AB Slim ${ }^{\circledR}$ were colored in different shades of green.

\section{Pharmaceutical Evaluation: HPLC Analysis}

The chromatographic analyses revealed that the mean values of sibutramine, phenolphthalein, and sildenafil content in the different batches of $18 \mathrm{AB} \mathrm{Slim}{ }^{\circledR}$ units ranged from $1.54( \pm 0.05)$ to $3.25( \pm 0.05) \mathrm{mg}, 32.09( \pm 1.67)$ to $40.13( \pm 3.68) \mathrm{mg}$, and $196.11( \pm 16.51)$ to 292.08 $( \pm 16.03) \mathrm{mg}$, respectively (Fig. 1).

Furthermore, 36 units of the analyzed Zotreem Plus ${ }^{\circledR}$ and 35 units of Zotreem Extra ${ }^{\circledR}$ were adulterated with phenolphthalein, sibutramine, and sildenafil. The mean values of sibutramine, phenolphthalein, and sildenafil content in the different batches of Zotreem Plus ${ }^{\circledR}$ ranged from $2.61( \pm 0.44)$ to $4.23( \pm 2.78) \mathrm{mg}, 34.64( \pm 9.96)$ to $53.66( \pm 8.92) \mathrm{mg}$, and $46.37( \pm 13.6)$ to $92.95( \pm 5.67) \mathrm{mg}$, respectively (Fig. 1). The mean values of sibutramine, phenolphthalein, and sildenafil content in the different batches of Zotreem Extra ${ }^{\circledR}$ ranged from $2.68( \pm 0.37)$ to $12.64( \pm 5.87) \mathrm{mg}, 34.56( \pm 9.34)$ to $63.35( \pm 11.66) \mathrm{mg}$, and $4.50( \pm 2.49)$ to $101.57( \pm 164.31) \mathrm{mg}$, respectively (Fig. 1).

Fig. 1. a Detection of adulterants in different batches of AB Slim ${ }^{\circledR}$ $(n=11)$, Zotreem Plus ${ }^{\circledR}(n=36)$, Zotreem Extra ${ }^{\circledR}(n=35)$, Malaysian Super $\operatorname{Slim}^{\circledR}(n=19)$, Chinese Super $\operatorname{Slim}^{\circledR}(n=46)$, and Metabolites ${ }^{\circledR}(n=25)$ sold in Egypt using a gradient high-performance liquid chromatography analysis. A reversed-phase $\mathrm{C}_{8}$ column was used $(15 \mathrm{~cm})$ along with a gradient mobile system, composed of $20 \mathrm{mM}$ aqueous ammonium formate (A) and acetonitrile (B) $\left(37^{\circ} \mathrm{C}, 1 \mathrm{~mL} / \mathrm{min}\right.$ flow rate, $32 \mathrm{~min}$ run time). The gradient elution program started with an isocratic gradient of A:B 90:10 (v/v) for $3 \mathrm{~min}$ (0th to $3 \mathrm{rd} \mathrm{min).} \mathrm{The} \mathrm{ratio} \mathrm{of} \mathrm{A} \mathrm{linearly} \mathrm{decreased}$ to $50 \%$ within $2 \mathrm{~min}$ ( $3 \mathrm{rd}$ to 5 th $\mathrm{min}$ ) and was sustained at the same ratio for $2 \mathrm{~min}$ ( 5 th to 7 th $\mathrm{min}$ ). The composition of the mobile phase linearly changed to $A: B \quad 25: 75(v / v)$ for 2 min (7th to 9th $\mathrm{min}$ ), 15:85 (v/v) for $2 \mathrm{~min}$ (9th to 11th $\mathrm{min}$ ), 5:95 (v/v) for $11 \mathrm{~min}$ (11th to 22nd $\mathrm{min}$ ), and finally 90:10 (v/v) for $10 \mathrm{~min}$ (22nd to 32nd min). b-e A photodiode array detector was used at $\lambda_{\max }$ of 285,213 , and $224 \mathrm{~nm}$. The individual bar charts represent the amounts of each of the four adulterants in the individual batches. b Sibutramine at $\lambda_{\max }$ of $224 \mathrm{~nm}$. c Phenolphthalein at $\lambda_{\max }$ of 285 $\mathrm{nm}$. d Sildenafil at $\lambda_{\max }$ of $224 \mathrm{~nm}$. e Orlistat at $\lambda_{\max }$ of $213 \mathrm{~nm}$. f Amounts of sibutramine, phenolphthalein, sildenafil, and orlistat across the different batches of the analyzed products. ns, $p>0.05$; ${ }^{*} p \leq 0.05,{ }^{* *} p \leq 0.01,{ }^{* * *} p \leq 0.001,{ }^{* * * *} p \leq 0.0001$.

Assessment of Adulterated Herbal

Slimming Supplements
Both Chinese Super Slim ${ }^{\circledR}(n=46)$ and Malaysian Super Slim ${ }^{\circledR}(n=19)$ were adulterated with sibutramine and sildenafil. The mean values of sibutramine in Chinese Super Slim ${ }^{\circledR}$ and Malaysian Super Slim ${ }^{\circledR}$ ranged from $2.44( \pm 2.10)$ to $0.80( \pm 0.15) \mathrm{mg}$ and $0.18( \pm 0.05)$ to $2.00( \pm 1.54) \mathrm{mg}$, respectively. On the other hand, the mean values of sildenafil in Chinese Super Slim ${ }^{\circledR}$ and Malaysian Super Slim ${ }^{\circledR}$ ranged from $36.42( \pm 4.51)$ to $49.04( \pm 9.34) \mathrm{mg}$ and $60.20( \pm 7.79)$ to $79.89( \pm 25.56)$ $\mathrm{mg}$, respectively. The mean values of sibutramine and orlistat content in the different batches of Metabolites ${ }^{\circledR}$ (25 analyzed ampoules) ranged from $0.23( \pm 0.05)$ to $0.26( \pm 0.01) \mathrm{mg}$ and $0.10( \pm 0.15)$ to $0.45( \pm 0.40) \mathrm{mg}$, respectively (Fig. 1).

\section{Pharmacopeial Tests: Weight Variation Assessment} and Disintegration Test

The mean values for weight variation of the Zotreem Plus $^{\circledR}$ batches were 222.06, 184.36, 183.31, 188.70, 251.82 , and $239.98 \mathrm{mg}$. In the case of the Malaysian Super Slim ${ }^{\circledR}$ batches, the mean values for weight variation were $225.71,217.47,270.48,264.09$, and $271.83 \mathrm{mg}$. As for the AB Slim ${ }^{\circledR}$ batches, the mean values for weight variation were 387.03 and $357.60 \mathrm{mg}$. The mean values for weight variation of the Zotreem Extra ${ }^{\circledR}$ batches were $188.70,251.82$, and $239.98 \mathrm{mg}$. In the case of the Chinese Super Slim ${ }^{\circledR}$ batches, the mean values for weight variation were 273.81, 265.22, 264.09, 274.73, 261.40, and $271.07 \mathrm{mg}$. The capsule content weight across batches ranged from 172.3 to $273.3 \mathrm{mg}$ for Zotreem Plus ${ }^{\circledR}$, from 195.6 to $294.3 \mathrm{mg}$ for Malaysian Super $\operatorname{Slim}^{\circledR}$, from 308.8 to $415.2 \mathrm{mg}$ for AB Slim ${ }^{\circledR}$, from 172.30 to 273.30 $\mathrm{mg}$ for Zotreem Extra ${ }^{\circledR}$, and from 223.90 to $294.30 \mathrm{mg}$ for Chinese Super Slim ${ }^{\circledR}$.

All products, except $A B$ Slim $^{\circledR}$, showed statistically significant differences in weight variability $(p<0.01)$ and heterogeneity in capsule content across the different batches analyzed $(p<0.05)$. Three different batches of Zotreem Plus ${ }^{\circledR}(n=18)$, Zotreem Extra ${ }^{\circledR}(n=18)$, Chinese Super $\operatorname{Slim}^{\circledR}(n=18)$, and Malaysian Super Slim ${ }^{\circledR}$ $(n=18)$ passed the disintegration test, while 3 batches of AB Slim ${ }^{\circledR}(n=30)$ failed it.

\section{Microbiological Evaluation}

TAMC and TYMC

The TAMC and TYMC of 3 different batches of each brand were all $>10^{4}$ colony-forming units $(\mathrm{CFU}) / \mathrm{mL}$ on tryptic soy agar plates and $>10^{3} \mathrm{CFU} / \mathrm{mL}$ on Sabouraud dextrose plates, respectively (Fig. 2). The accepted USP limit is $10^{3} \mathrm{CFU} / \mathrm{mL}$ for TAMC and $10^{2} \mathrm{CFU} / \mathrm{mL}$ for 


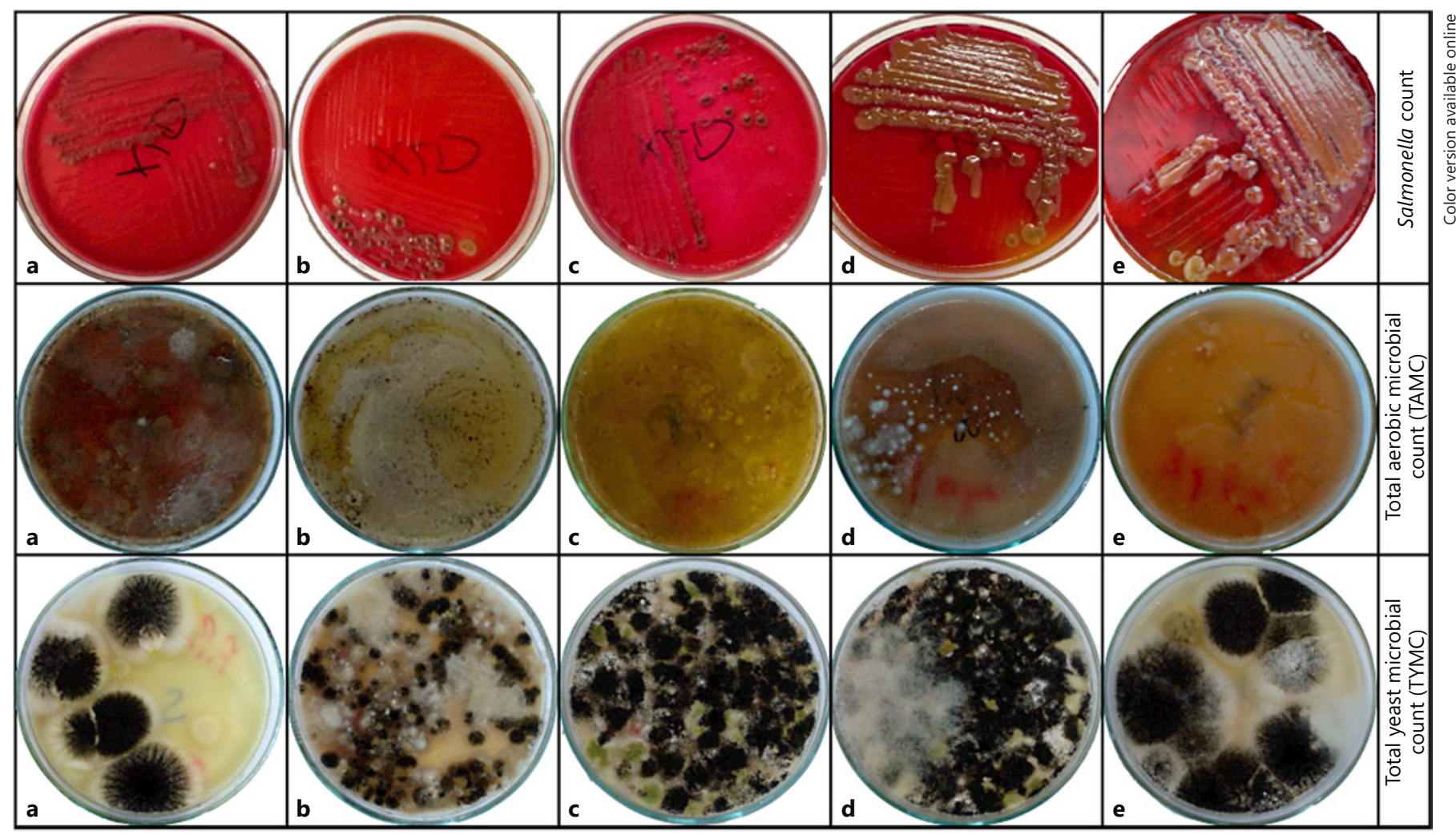

Fig. 2. Microbial evaluation of $A B \operatorname{Slim}^{\circledR}$ (a), Chinese Super Slim ${ }^{\circledR}$ (b), Malaysian Super Slim ${ }^{\circledR}$ (c), Zotreem Ex$\operatorname{tra}^{\circledR}(\mathbf{d})$, and Zotreem Plus ${ }^{\circledR}(\mathbf{e})$. The upper, middle, and lower panels show contamination with Salmonella on xylose lysine deoxycholate agar plates (colonies with a black center), the total aerobic microbial count (TAMC), and the total yeast microbial count (TYMC), respectively.

TYMC [19]. Thus, the microbial counts exceeded the acceptable USP limit in all of the analyzed weight loss products, indicating that these products failed the TAMC and TYMC tests.

\section{Escherichia coli}

Three different batches of each brand $\left(\mathrm{AB} \mathrm{Slim}{ }^{\circledR}\right.$, Zotreem Plus ${ }^{\circledR}$, Malaysian Super Slim ${ }^{\circledR}$, and Chinese Super Slim ${ }^{\circledR}$ ) were found to be contaminated with $E$. coli. The inoculation of MacConkey Broth with aliquots from the culture of 3 different batches of each brand in TSB/Tween 80 , followed by cultivation on MacConkey agar plates, resulted in the growth of red colonies in all weight loss products analyzed except Zotreem Extra ${ }^{\circledR}$. Additionally, the indole production test, a confirmatory test for the detection of E. coli, revealed the formation of a red upper reagent layer, confirming the identity of the contaminating microorganism to be E. coli.

\section{Salmonella}

All of the analyzed products, including 3 different batches of each brand (ABSlim ${ }^{\circledR}$, Zotreem Plus ${ }^{\circledR}$, Zotreem Extra $^{\circledR}$, Malaysian Super Slim ${ }^{\circledR}$, and Chinese Super Slim ${ }^{\circledR}$ ), were contaminated with Salmonella, as illustrated in Figure 2. The Rappaport Vassiliadis tubes inoculated with aliquots from subcultures of the analyzed slimming products in TSB/Tween 80 produced visible turbidity. Furthermore, subsequent cultivation on xylose lysine deoxycholate agar plates resulted in the growth of colonies with a black center, indicating contamination with Salmonella.

\section{Sterility Test}

Suitability tests, including medium sterility and growth promotion of aerobes, anaerobes, and fungi, were done before the sterility test according to the guidelines of USP $40-\mathrm{NF} 35$ [19]. A clearly visible growth of microorganisms was obtained in the suitability test; hence, the 
sterility test was conducted without any modification. Fluid thioglycollate medium and soybean casein digest medium were turbid upon inoculation with a membrane filter used to filter one of the 3 different batches of Metabolites ${ }^{\circledR}$ injections, indicating failure to pass the sterility test.

\section{Cross-Sectional Observational Retrospective \\ Prevalence Study}

The cross-sectional observational retrospective prevalence study showed that $8.2,23.9$, and $67.8 \%$ were normal-weight participants (BMI 18.5-24.9), overweight participants (BMI 25-30), and obese participants (BMI $<30)$, respectively. Furthermore, $46.4 \%(n=238)$ of the adult participants had a disease history, such as hypertension $(26.0 \%)$ and heart disorders (8.4\%). A majority of the participants had bachelor's degrees (61.0\%). $89.5 \%$ of the adult participants tried to follow healthy diet plans, but only $16.2 \%$ succeeded in maintaining their healthy diet plans. The percentage of participants who considered nutraceutical OTC products safer than approved weight loss products was $84.4 \%(n=433)$. Alarmingly, the percentage of adult participants that used illegal weight loss products, including Super Slim $^{\circledR}$, Zotreem Plus ${ }^{\circledR}, \mathrm{AB}$ Slim ${ }^{\circledR}$, Zotreem Extra ${ }^{\circledR}$, and Metabolites ${ }^{\circledR}$, was $45.4 \%(n=233)$. The main source of the weight loss products were pharmacies (59.5\%; $n=305)$; other sources included diet clinics, online stores, TV shopping, and other undeclared sources.

With respect to safety, adult users who consumed Super Slim ${ }^{\circledR}$ (Table 1) suffered from diarrhea (65.4\%), appetiteloss (76.9\%), dizziness (32.7\%), tachycardia (34.6\%), and dry throat (40.4\%). In the case of Zotreem Plus ${ }^{\circledR}$ (Table 1), adult users suffered from diarrhea (45.9\%), appetite loss (97.3\%), tachycardia (67.6\%), depression (56.8\%), and dry throat (73.0\%). Users of AB Slim ${ }^{\circledR}$ (Table 1) suffered from diarrhea (48\%), appetite loss (78\%), hypertension $(10 \%)$, dizziness $(28 \%)$, tachycardia (32\%), blurred vision (18\%), depression (34\%), suicidal thoughts (4\%), skin rash (4\%), and dry throat (70\%).

With respect to efficacy, the results of the study revealed a wide variation in the efficacy of both prescription medications and OTC nutraceuticals. For instance, in the case of prescription medications, 52.3 and $22.5 \%$ of the subjects surveyed considered the efficacy of Orly ${ }^{\circledR}$ generics moderate and strong, respectively, while 21.7 and $51.9 \%$ of the subjects surveyed considered the efficacy of Chromax ${ }^{\circledR}$ generics weak and moderate, respectively. $14.3 \%$ of the subjects surveyed considered Chitocal ${ }^{\circledR}$ and Cidophage ${ }^{\circledR}$ as ineffective. In the case of nutraceutical

Assessment of Adulterated Herbal

Slimming Supplements
OTC weight loss products, $65.4,66.6,67,78.1$, and $33 \%$ of the adult participants believed that the efficacy of Super Slim ${ }^{\circledR}$, Zotreem Plus ${ }^{\circledR}$, AB Slim ${ }^{\circledR}$, Zotreem Extra ${ }^{\circledR}$, and Metabolites ${ }^{\circledR}$ ranged from moderate to strong.

\section{Discussion}

Life-threatening outcomes may result if customers use a single dose of products containing phenolphthalein, sildenafil, sibutramine, and orlistat, with no real efficacy. Based on the claim that these products are safe, consumers may decide to use double or triple doses, which may lead to highly toxic levels of adulterants. In a possible scenario, a user consumes 1 capsule of Zotreem Extra ${ }^{\circledR}$, which might contain $2.6 \mathrm{mg}$ of sibutramine, $4.5 \mathrm{mg}$ of sildenafil, and $3.4 \mathrm{mg}$ of phenolphthalein, with no real efficacy. Later, the user may decide to consume 2 capsules, each containing $12.64 \mathrm{mg}$ of sibutramine, $101 \mathrm{mg}$ of sildenafil, and $63 \mathrm{mg}$ of phenolphthalein. Such a scenario would be deadly in the case of users with cardiovascular disorders. These levels could be lethal, especially as the target audience is informed that these products are natural and safe. Disturbingly, the target audiences of these products are obese individuals and immunocompromised patients, often with heart and blood pressure problems.

To our knowledge, there are no reports from Egypt and the Middle East with respect to adulteration or counterfeiting of weight loss nutraceuticals. One study by ElAgouri et al. [20] analyzed illegal male enhancement nutraceuticals in Egypt in 2013. A study investigating weight loss nutraceuticals sold in Iran detected sibutramine, phenolphthalein, and bumetanide in Magic Slim, Green Lean Super Slim, Original Super Slim, Fast Slim, Herbaceous Essence, and Fat Loss [15]. Alarmingly, the FDA reported that many illegal weight loss nutraceuticals in the USA, such as ABX Weight Loss, Asia Slim Capsules, and Fruta Planta Life (Garcinia Cambogia Premium), were adulterated with sibutramine $[21,22]$. While it was approved by the FDA, Propell Platinum was found to be adulterated with sibutramine and phenolphthalein [22]. Another FDA-approved nutraceutical, Smart Lipo 365, was found to contain desmethylsibutramine, sibutramine, and phenolphthalein [23].

Microbial contamination has many hazardous effects on patients and may decrease or eliminate the therapeutic effect of the active constituents [24]. It could also convert the main active constituent into toxic metabolites, which may be hazardous [25]. Moreover, it may alter the organ- 
Table 1. Side effects, efficacy, and pattern of use of prescription medications (Orly ${ }^{\circledR}$, Chromax $^{\circledR}$, Chitocal ${ }^{\circledR}$, and Cidophage ${ }^{\circledR}$ generics) or nutraceutical OTC products (Super Slim ${ }^{\circledR}$, Zotreem Plus ${ }^{\circledR}$, AB Slim ${ }^{\circledR}$, Zotreem Extra ${ }^{\circledR}$, and Metabolites ${ }^{\circledR}$ ) for weight loss in a crosssectional observational retrospective prevalence study

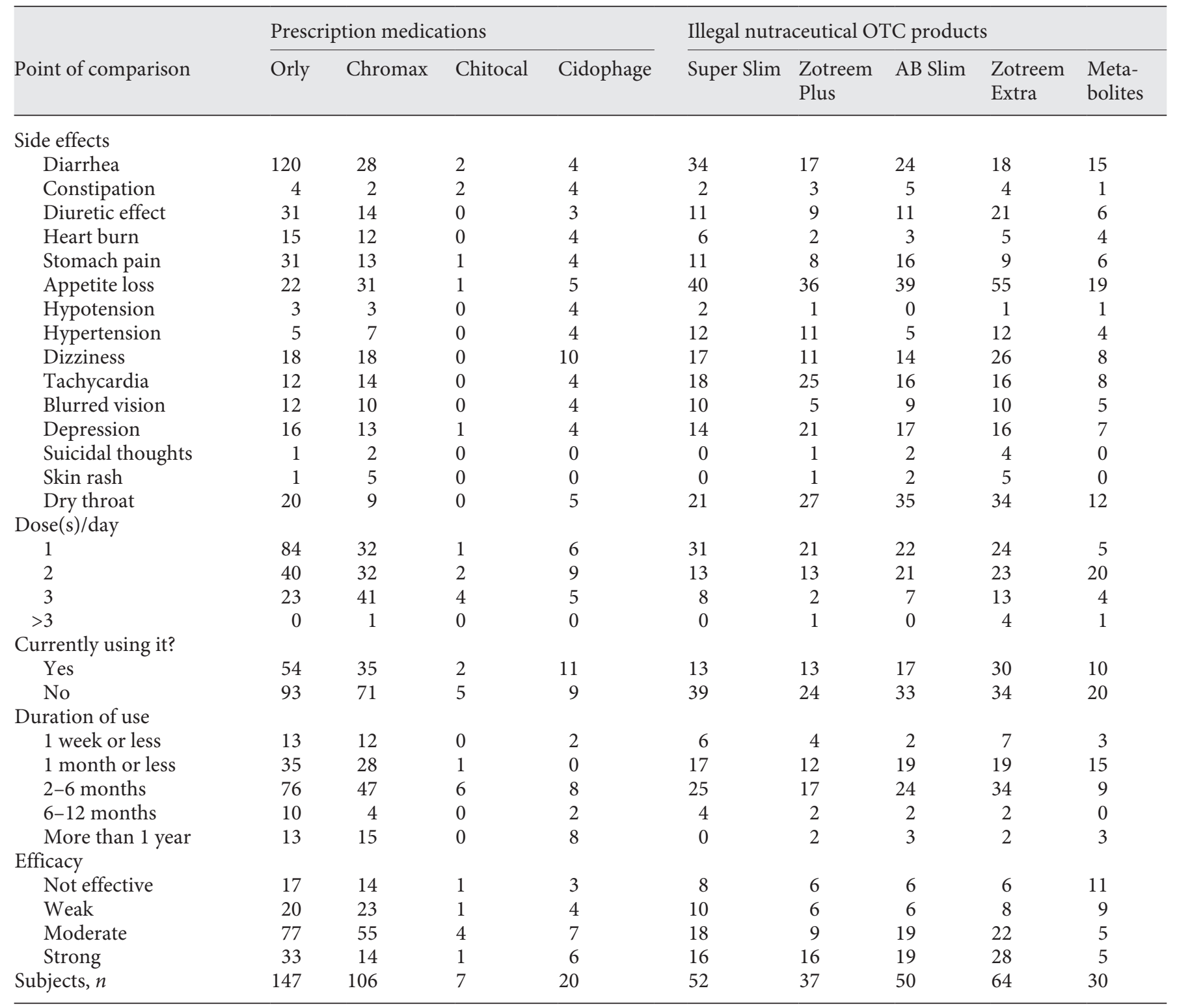

oleptic, physical, and chemical properties of the drug [25]. Our data showed that the microbial count in $100 \%$ of the unapproved weight loss products exceeded the acceptable USP limit, which should have signified a failure of these products to pass the TAMC and TYMC tests, indicating a poor bacteriological quality of the raw materials, manufacturing process, or packaging process, contamination by workers, or inferior storage or transportation conditions [25]. Contamination of products with $E$. coli and Salmonella is an indication of possible fecal contamination [25]. The presence of these pathogens or their toxins may cause many undesirable effects, ranging from diarrhea or abdominal pain to death. Unfortunately, there are no studies on the microbial safety of herbal weight loss products especially in the Middle East. To our knowledge, the current study is the first to report microbially contaminated nutraceuticals sold in the Middle East. 
Table 2. Investigated products marketed in Egypt as herbal supplements for weight loss

\begin{tabular}{|c|c|c|}
\hline Zotreem Plus & $\begin{array}{l}\text { - Coix seed } \\
\text { - Lotus leaf } \\
\text { - Radish seed } \\
\text { - Hawthorn fruit } \\
\text { - Japanese sea tanpl }\end{array}$ & $\begin{array}{l}\text { - Appetite suppressant } \\
\text { - Boosting up the metabolic rate up to } 18 \text { times } \\
\text { - Fat burner (it burns fat especially in the lower part of the body including the waist, } \\
\text { hips, and legs) } \\
\text { - Enhancing energy level and immunity } \\
\text { - Only } 1 \text { capsule of Zotreem Plus destroys fat cells }\end{array}$ \\
\hline Super Slim & $\begin{array}{l}\text { - Konicing nut } \\
\text { - Gamboge fruit } \\
\text { - Pomegranate } \\
\text { - Apple } \\
\text { - Kiwi fruit } \\
\text { - Konjac extractive powder } \\
\text { - Sweet potato fiber } \\
\text { - No ephedrine or other harmful } \\
\text { chemicals or drugs } \\
\text { - Made up of } 100 \% \text { natural herbs }\end{array}$ & $\begin{array}{l}\text { - Super Slim suppresses the appetite by controlling excessive eating and cravings } \\
\text { - Boosting up the metabolic rate } \\
\text { - Breaking down fats, carbohydrates, and protein } \\
\text { - Energy booster } \\
\text { - Super Slim elevates the body's energy level, which leads to quick burning of } \\
\text { calories } \\
\text { - Prevention of fat absorption } \\
\text { - Antioxidant } \\
\text { - Safe weight loss } \\
\text { - No prescription needed }\end{array}$ \\
\hline AB Slim & $\begin{array}{l}\text { - Rhizoma Atractylodis } \\
\text { macrocephalae } \\
\text { - Cassia seed } \\
\text { - Liquorice } \\
\text { - Dried ginger } \\
\text { - Ginseng } \\
\text { AB Slim is composed of natural } \\
\text { ingredients; furthermore, AB Slim } \\
\text { does not have any chemical } \\
\text { ingredients }\end{array}$ & $\begin{array}{l}\text { - AB Slim reduces the fat percentage in the blood by } 50-70 \% \\
\text { - It converts fat and cellulite into energy } \\
\text { - Enhancing sexual efficiency } \\
\text { - AB Slim helps to get a perfect body shape } \\
\text { - Relief the stomach pain and bloating } \\
\text { - Constipation treatment } \\
\text { - Removing blackness around the eyes and cleansing the facial skin } \\
\text { - AB Slim received the Gold Medal for Merit in Excellence and Quality from } \\
\text { "TATWIJ" and a GMP global certificate by the ministries of health and the } \\
\text { embassies of different countries } \\
\text { - AB Slim was approved by the Ministry of Public Health in Lebanon } \\
\text { - AB Slim is considered safe and clinically verified by the United Arab Emirates }\end{array}$ \\
\hline
\end{tabular}

The claimed ingredients and label claim are detailed for each product.

The cross-sectional observational retrospective prevalence study revealed many observations regarding consumption patterns as well as the efficacy, safety, and quality of these products. In the current study, $84 \%(n=433)$ of the participants believed that herbal products were safer than prescription weight loss products. This misconception could be based on the lack of awareness of the hazardous effects of these products and the undeclared adulteration. Moreover, our study illustrates that con- sumers cannot grasp the regulatory distinction between nutraceuticals and legal prescription weight loss formulations.

In the current study, adult users who consumed the analyzed products suffered from diarrhea, appetite loss, dizziness, tachycardia, blurred vision, depression, suicidal thoughts, skin rash, hypertension, and dry throat. In a similar retrospective cohort study, Müller et al. [26] reported 17 documented cases of poisoning due to Chinese 
herbal slimming products in Germany. The main manifestations were tachycardia, arterial hypertension, headache, nausea, vomiting, and insomnia. Alarmingly, $46 \%$ $(n=238)$ of our participants had a history of diseases. Sildenafil and sibutramine could have had lethal side effects on those diseased participants, such as those with cardiac arrest, acute myocardial infarction, and severe hypertension [27]. Finally, all of the analyzed products were found to be heavily adulterated with sibutramine, orlistat, phenolphthalein, and levothyroxine. Based on the results of our analyses and the adulterants, we infer that the claims and ingredients listed for the products are inaccurate and misleading (Table 2). Sibutramine suppresses the appetite via blocking the reuptake of neurotransmitters including dopamine, norepinephrine, and serotonin. Orlistat inhibits lipase reversibly and prevents the absorption of approximately $30 \%$ of the dietary fat. Phenolphthalein was the main ingredient in many OCT laxatives until 1999.

\section{Conclusions}

There is a need to raise awareness on the lethal consequences of illegal nutraceuticals, which are marketed without any regulation and need for prescription. Strict laws to ban the marketing, television advertisement, and sale of these illegal products should be developed to protect consumers. Healthcare workers, including nutritionists, pharmacists, and healthcare providers, should be informed about the hazardous effects of these products. Pharmacies and clinics should be banned from selling adulterated and unlicensed drugs. Finally, reliable techniques should be utilized for the fast and accurate detection of adulterants and counterfeit products, such as near-infrared spectrophotometry or simple spectrophotometric analysis [20,28]. New portable devices for drug identification, such as the Stratio LinkSquare ${ }^{\circledR}$ pen spectrophotometer, have started to emerge in the market [28]. More research should be conducted on the optimization, validation, and modification of such devices for the easy detection of adulteration and counterfeiting.

\section{Disclosure Statement}

The authors have no conflicts of interest to disclose.

\section{References}

1 Gulati OP, Berry Ottaway P. Legislation relating to nutraceuticals in the European Union with a particular focus on botanical-sourced products. Toxicology. 2006 Apr;221(1):75-87.

2 Andlauer W, Fürst P. Nutraceuticals: a piece of history, present status and outlook. Food Res Int. 2002;35(2-3):171-6.

3 Fleisher LA, Roizen MF, Roizen JD. Essence of anesthesia practice. 4th ed. Philadelphia, PA: Elsevier and Saunders, 2018.

4 Haneef J, Shaharyar M, Husain A, Rashid M, Mishra R, Siddique NA, et al. Analytical methods for the detection of undeclared synthetic drugs in traditional herbal medicines as adulterants. Drug Test Anal. 2013 Aug;5(8):607-13.

5 Nounou MI, Ko Y, Helal NA, Boltz JF. Adulteration and counterfeiting of online nutraceutical formulations in the United States: time for intervention? J Diet Suppl. 2018 Sep; 15(5):789-804.

6 Bagchi D, Preuss GH. Obesity: epidemiology, pathophysiology, and prevention. 2nd ed. Boca Raton, FL: CRC Press; 2012.

7 Bass IS. Dietary supplement regulation: a comprehensive guide. Washington, DC: Food and Drug Law Institute; 2011.
8 Musaiger AO, Al-Hazzaa HM. Prevalence and risk factors associated with nutrition-related noncommunicable diseases in the Eastern Mediterranean region. Int J Gen Med. 2012;5:199-217.

9 National Institute of Diabetes and Digestive and Kidney Diseases (NIDDK). Prescription medications for the treatment of obesity: Weight-Control Information Network. Bethesda, MD: NIDDK; 2013, 2014.

10 Papavramidou N, Christopoulou-Aletra H. Management of obesity in the writings of Soranus of Ephesus and Caelius Aurelianus. Obes Surg. 2008 Jun;18(6):763-5.

11 Wells $\mathrm{H}$. The physiology and therapeutics of the thyroid gland and its congeners. JAMA. 1897;XXIX(18):897-904.

12 United Nation Office on Drugs and Crime (UNODC). Counterfeit goods: a bargain or a costly mistake? Transnational organized crime. Vienna, Austria: UNODC; 2016.

13 Khazan M, Hedayati M, Kobarfard F, Askari S, Azizi F. Identification and determination of synthetic pharmaceuticals as adulterants in eight common herbal weight loss supplements. Iran Red Crescent Med J. 2014 Mar; 16(3):e15344.
14 Rebiere H, Guinot P, Civade C, Bonnet PA, Nicolas A. Detection of hazardous weightloss substances in adulterated slimming formulations using ultra-high-pressure liquid chromatography with diode-array detection. Food Addit Contam Part A Chem Anal Control Expo Risk Assess. 2012;29(2):16171.

15 Diet pill addiction and misuse: addiction education [Internet]. Available from: http:// www.addictionsearch.com.

16 US Food and Drug Adminstration (FDA). Questions and answers about FDA's initiative against contaminated weight loss products [Internet]. 2018. Available from: https:// www.fda.gov/Drugs/ResourcesForYou/Consumers/QuestionsAnswers/ucm136187.htm.

17 United States Pharmacopeial Convention. (905) Uniformity of dosage units; The United States Pharmacopeia (USP 40-NF 35). Volume 1. Baltimore, MD: United Book Press, Inc.; 2017. pp. 802-6.

18 United States Pharmacopeial Convention. (701) Disintegration; The United States Pharmacopeia (USP 40-NF 35). Volume 1. Baltimore, MD: United Book Press, Inc.; 2017. pp. 584-6. 
19 United States Pharmacopeial Convention. (61) Microbiological examination of nonsterile products: microbiological enumeration tests; The United States Pharmacopeia (USP 40-NF 35). Volume 1. Baltimore, MD: United Book Press, Inc.; 2017. pp. 117-23.

20 ElAgouri G, ElAmrawy F, ElYazbi A, Eshra A, Nounou MI. Male enhancement nutraceuticals in the Middle East market: claim, pharmaceutical quality and safety assessments. Int J Pharm. 2015 Aug;492(1-2):109-19.

21 US Food and Drug Adminstration (FDA). Public notification: Asia Slim Capsules contains hidden drug ingredients. 2018. Available from: https://www.fda.gov/Drugs/ResourcesForYou/Consumers/BuyingUsingMedicineSafely/MedicationHealthFraud/ucm586347. htm.
22 US Food and Drug Adminstration (FDA). Public notification: Propell Platinum contains hidden drug ingredients. 2018. Available from: https://www.fda.gov/Drugs/ResourcesForYou/Consumers/BuyingUsingMedicineSafely/MedicationHealthFraud/ucm 493068 . htm.

23 US Food and Drug Adminstration FDA. FDA recall: Smart Lipo 365 issues voluntary nationwide recall of Smart Lipo due to undeclared sibutramine, desmethylsibutramine and phenolphthalein. 2015. Available from: http://www.gtbslaw.com/fda-alerts/.

24 Pullirsch D, Bellemare J, Hackl A, Trottier YL, Mayrhofer A, Schindl H, et al. Microbiological contamination in counterfeit and unapproved drugs. BMC Pharmacol Toxicol. 2014 Jun;15(1):34.
25 Ratajczak M, Kubicka MM, Kamińska D, Sawicka P, Długaszewska J. Microbiological quality of non-sterile pharmaceutical products. Saudi Pharm J. 2015 Jul;23(3):303-7.

26 Müller D, Weinmann W, Hermanns-Clausen M. Chinese slimming capsules containing sibutramine sold over the Internet: a case series. Dtsch Arztebl Int. 2009 Mar;106(13): 218-22.

27 Wooltorton E. Obesity drug sibutramine (Meridia): hypertension and cardiac arrhythmias. CMAJ. 2002 May;166(10):1307-8.

28 Stratio Inc. Broadband, handheld and affordable spectrometer (Linksquare) for fast and reliable drug identification. San Jose, CA: Stratio, Inc.; 2017. 